\title{
Effective Cross-cultural Relationships in Multinational Corporations. Foreign Subsidiaries' Viewpoint
}

\author{
Małgorzata Rozkwitalska \\ Management Department \\ Gdansk School of Banking, \\ Gdansk, Poland \\ mrozkwitalska@wsb.gda.pl
}

\begin{abstract}
Since multinational corporations (MNCs) operate in many distant cultures, cross-cultural relationships are their dayto-day reality that affect efficiency of their multinational workforce. Therefore, MNCs are expected to learn how to manage such relationships to establish fruitful cooperation among their employees and with external stakeholders. MNCs need to understand barriers to and facilitators of effective cross-cultural relationships. The identification of them is the goal of this paper. Basing on the literature review, the author's concept of cultural barriers and her research, the paper lists barriers to crosscultural interpersonal interactions and discusses the empirical findings on what contributes to effective cooperation within MNCs. Since MNCs headquarters' perspective is more common in international business' literature and research, foreign subsidiaries' viewpoint is emphasized in this paper.
\end{abstract}

Keywords-cross-cultural relationships/interactions; cultural barriers; foreign subsidiary; multinational corporation

\section{INTRODUCTION}

Multinational corporations (MCNs) investing and operating in many distant markets create foreign affiliates or subsidiaries, participate in international joint ventures and strategic alliances, use overseas supplies, etc. As a result, they function as a system consisting of many subunits working in a divergent environmental context, including national cultures, employing multicultural workforce, negotiating with foreign contractors and satisfying needs of other groups of stakeholders in each country of operation. Therefore, on a daily basis they establish and maintain relationships that, by their very nature, are crosscultural. If there are barriers to cross-cultural relationships in MNCs, the effectiveness of multicultural workforce will be likely to drop due to obstacles to tasks realization. By

This work was partially funded by Gdansk School of Banking in Poland due to its financial contribution to the costs of preparing the paper and the author's participation in BiZStrategy 2013 Conference. contrast, effective cross-cultural interactions may e.g. communication and increase the satisfaction level of personnel [1]. Therefore, understanding of barriers to and facilitators of effective cross-cultural relationships in MNCs is of crucial importance. This paper is to foster such an understanding by developing the theoretical concept in the first main section of the article and then presenting the research findings in the subsequent one.

The ample literature on international business (IB) made MNCs the main, vital and even fascinating object of study, among other things, due to their impact on host and home countries, and as a result, on the world economy. Various issues have been analyzed so far with regards to MNCs, e.g. their modes of entry into foreign markets, internationalization paths, knowledge transfer within subunits, organizational design, strategy, etc. [2].

The literature on MNCs' subsidiaries is also rich and growing. However, the authors here were primarily focused on differentiated subsidiaries' roles within the MNCs' systems. One of the major contributions of this stream is the idea that the subsidiary can actively shape its position within a MNC system. Another IB literature stream, the headquarterssubsidiary relationship one, was mostly concerned with the control over foreign subsidiaries exercised by the centre [3]. What is missing in the IB literature is the lack of focus on internal and external cross-cultural relationships of a MNC's subsidiaries' and the headquarters' (HQ) personnel within the MNC's whole system.

Cross-cultural relationships are the core of studies in the intercultural management (IM) field. Although one of its perspectives, named geocentric, concentrates on multinational organizations, it rather assumes that MNCs are beyond cultures and therefore it seeks to explain what approaches to managing allow them to operate in many locations in the world. Nevertheless, the most recent perspective in IM, the synergistic approach, is concerned, among other things, with 
the behavior of people in MNCs [4]. It holds the assumption that cross-cultural interactions can and should be managed to help multinational organizations to earn profits from their operations in a diverse environment [5].

Since the study conducted in this paper concentrates on cross-cultural interactions, it can be numbered among the synergistic stream in IM. Hence it reflects a local perspective on cross-cultural relationships in MNCs, the study also fills the gap of the IB literature identified above. Moreover, the local perspective on this issue is of particular importance since forcign subsidiarics "carry the main load related to handling the cultural challenges" [6], consequently emphasizing the previously mentioned active role of the subsidiary in a MNC's system.

\section{EFFECTIVENESS OF CROSS-CULTURAL RELATIONSHIPS - LITERATURE REVIEW AND THEORETICAL CONCEPT}

\section{A. Cross-cultural Relationships Definition and Model}

Cross-cultural relationships or cross-cultural interactions refer in this paper to all the types of internal and external, direct and indirect contacts of people in each subsystem of MNCs, e.g. interactions in multicultural teams, subordinatesuperior relationships, negotiations, office contacts with other foreign affiliates of a MNC or with foreign partners, training, business trips, carrying out tasks, knowledge sharing, etc. They imply how members of various cultures affect one another, behave in particular situation and are a part of social interaction (see Fig. 1). They can be associated with a communication process since communication is perceived as a complex system of behaviors [7].

\begin{tabular}{|c|c|c|}
\hline \multicolumn{3}{|c|}{ 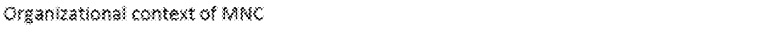 } \\
\hline \multirow{3}{*}{ 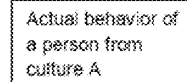 } & Q g. Eiving onders vis direct contact & \multirow{3}{*}{ 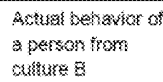 } \\
\hline & E.g tewmoryog & \\
\hline & 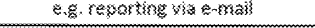 & \\
\hline
\end{tabular}

Fig. 1. Cross-cultural relationships in MNCs.

Culture provides patterns of cognition and behaviors shared by a group that are reflected in social interaction processes and which form the frames for such an interaction [8]. However, behaviors are also contingent on, so-called, genetic predispositions as well as situational necessities and the environmental context (e.g. organizational system) [9]. Moreover, individuals' behaviors are also mentally programmed by personality (see Fig. 2) [10].

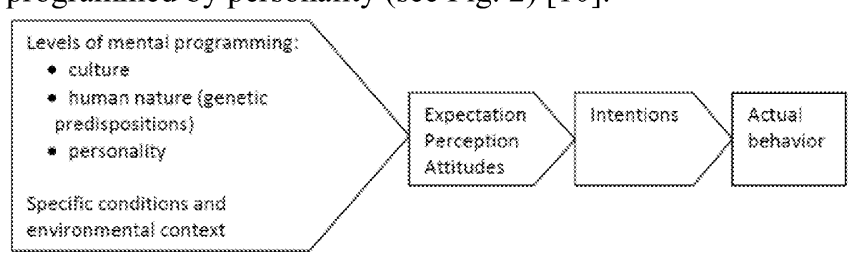

Fig. 2. Simplified model of human behavior.
In MNCs various overlapping subcultures exist that are influenced by national and organizational cultures of each MNC's subunit. They affect interpersonal interactions in a complex way since MNC's subcultures may foster both complimentary and conflicting patterns of behavior [11]. The latter may produce barriers to cross-cultural relationships in MNCs and therefore efficient management methods to ensure mutual cooperation between parent, subsidiary companies and external stakeholders are required. Hence, managing crosscultural relationships in order to enable a MNC's employees to work efficiently is a scrious challenge. Appropriateness of a particular behavior in a given cross-cultural setting is of vital importance. Defined as the extent to which the observed behaviors of a given participant of a cross-cultural interaction are congruent with behavioral norms (affected by culture) of another participant of this interaction [12], it generates positive reactions and enhances the quality of relationships in an organization [13]. Such appropriateness may later increase effectiveness of cross-cultural relationships in MNCs, namely goals achievement when mutual cooperation is established. Therefore, effective cross-cultural relationships in MNCs can be understood as interactions that result in mutual cooperation aimed at goals achievement.

\section{B. Barriers to Cross-cultural Relationships}

Interpersonal relationships in MNCs are affected by the national cultures of managers and employees, a specific organizational context of a MNC and individual characteristics of interacting people (see Fig.1 and 2). These factors differentiate human behavior and impact on an individual's evaluation of its appropriateness. They all determine "preferences for, and responses to, the behaviors of others" [13] and can be perceived as barriers to cross-cultural relationships in MNCs.

Since "a cultural barrier is everything that may impede cross-cultural interactions" [14], as a result, hindering goals achievement through lowering the effectiveness of crosscultural relationships in a whole MNC's system. Basing on previously identified determinants of human behaviors in a cross-cultural setting, the author indicated three sources of barriers [15]:

1) National culture bonded barriers to cross-cultural interactions ( or $_{2}$ in other words ${ }_{2}$ cultural distance embedded barriers) as a result of people mental programming by their national culture. The following hindrances can be identified in this category: cultural distance, cultural shock, cultural stereotypes and auto-stereotypes, prejudices and national ethnocentrism.

Traditionally, scholars have associated negative consequences to cultural distance impact on management of foreign subsidiaries and human interactions in MNCs (see e.g. [16]-[18]). It was noticed that cultural distance hampers the development of cultural competence (CC) of individuals in a cross-cultural setting by hindering their appropriate response 
to a given situation at work [19]. Although some recent research findings have emphasized a more balanced approach to cultural distance by revealing its positive influence on organizations as well [20], it still can be perceived as a barrier if MNCs' staff members fail to manage the cultural challenges properly.

Cultural distance may expose individuals in MNCs on longer overseas assignments to culture shock that reflects frustration, confusion and stress of an individual who, at least initially, faces difficulties in adapting to a foreign environment. These difficultics may decrease an individual's effectiveness, develop his/her negative attitudes towards the members of the new culture and consequently hamper the cross-cultural interactions [21].

Generally, people's interactions in MNCs can be also affected by their predisposition to infer the traits to others basing on cultural stereotypes. Self-perception of a particular cultural group, i.e. a cultural auto-stereotype, impacts on the attitudes towards other nations as well. Stereotypes and autostereotypes pose a risk of too far-reaching and unfair generalizations which may lead to prejudices and self-fulfilling prophecies, negatively affecting the quality of interpersonal interactions [22].

Finally, the category of national culture bonded barriers to cross-cultural relationships includes ethnocentrism reflecting a certain cultural group's sense of superiority over the others. It is perceived as a tremendous barrier to the interactions of people in MNCs since it may strengthen a parent company's institutional ethnocentrism (see point 2), induce individuals to exhibit the ethnocentric or parochial attitude and to use the cultural dominance approach to multiculturalism [15], [19].

2) Organizational barriers to cross-cultural interactions due to interpersonal relationships that occur in a certain organizational context of a MNC. As MNCs vary with regards how they are organized and managed, they can create an organizational environment that is conducive to cross-cultural interactions or increase cultural barriers, causing ineffective interpersonal relationships, e.g. by affecting how individuals evaluate the appropriateness of expected and enacted behaviors [12]. This category includes numerous factors from among which the following seem to be the most basic and significant: the headquarters' strategic mindset and its institutional ethnocentrism, the level of a MNC's international experience and a culture gap [15]. They later affect, among other issues, Human Resource Management (HRM) practices, communication system and other organizational solutions in MNCs [15].

The headquarters' strategic mindset/predisposition determines several elements of organizational design such as communication patterns, staffing practices, organizational structure and culture which concerns human relationships of MNCs [23]. It affects frequency, intensity, and character of contacts within a MNC's system. Such a strategic predisposition may also foster a more or less responsive approach to managing foreign subsidiaries, where the latter (i.e. the ethnocentric predisposition) potentially produces more tension in interpersonal contacts. Some authors coined the term institutional ethnocentrism to emphasize the negative consequences of the HQ predisposition embedded in structures, processes and management mentalities to the development of cultural competence of individuals, stating further that CC needs organizational support [19].

The level of international experience of a MNC determines the level of accumulated experiential knowledge that can be used to overcome cultural barricrs by reducing the so-called psychic distance [24]-[25]. It can be assumed that the lower the psychic distance, the greater chances for appropriateness of behaviors exhibited by individuals in a cross-cultural setting [13]. Hence, MNCs with a relatively low level of international experience, e.g. at the initial stage of an internationalization process, may face more barriers to cross-cultural relationships.

If a subsidiary was established via cross-border merger or acquisition (M\&A), a risk of a culture gap occurs. It leads to differences in organizational subcultures of a MNC's various subunits and consequently requires a double-layered acculturation of expatriates complicating the adaptation process in multicultural surroundings [25]. Therefore, a culture gap decreases the appropriateness of behaviors, which may negatively affect contacts between people.

3) Individual rooted barriers to cross-cultural interactions due to the fact that individuals, by definition, affect one another and behave in interpersonal relationships. This category includes barriers depicted in Fig. 3.

\begin{tabular}{|c|c|c|c|}
\hline $\begin{array}{l}\text { Ethrnocentric } \\
\text { atrisudes }\end{array}$ & $\begin{array}{l}\text { Mispercention } \\
\text { Mistinteryretation } \\
\text { Misevaluation }\end{array}$ & 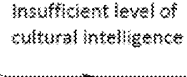 & 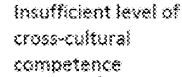 \\
\hline $\begin{array}{l}\text { insulficient } \\
\text { irsternational } \\
\text { experience }\end{array}$ & & $\begin{array}{l}\text { Individual traits: } \\
\text { age, eduscation, } \\
\text { ghysical status, }\end{array}$ & $\begin{array}{c}\text { Individuals } \\
\text { behavor in cress- } \\
\text { cultural }\end{array}$ \\
\hline
\end{tabular}

Fig. 3. Model of individual rooted barriers to cross-cultural relationships [15].

As reported by some scholars [21], [26]-[27], [42], appropriateness of behaviors in cross-cultural relationships is likely to increase if individuals were previously exposed to a foreign environment and therefore gained experience in this type of interactions.

Misperception/misinterpretation/misevaluation means that behaviors of people in a multicultural environment are influenced by, among other aspects, the culturally based individuals' perceptual filters. Their consequences are the subsequent: people see things inappropriately, assign wrong meanings to them, and then form an opinion which affects individuals' behaviors and the evaluation of the appropriateness of behaviors of others [21].

IM researchers proved that a lack of cultural intelligence $(C Q)$ or its insufficient level poses barriers to cross-cultural relationships [28]. The same is true if CC is considered and, what is more, $\mathrm{CQ}$ and $\mathrm{CC}$ are interrelated since an insufficient 
level of CQ creates obstacles to the development of CC [19].

It can be assumed that such an individual characteristics as age, education level, family status, etc. may affect crosscultural relationships, yet their role is not sufficiently examined by researchers. For instance, the IM literature on expatriate management stresses that a person on an overseas assignment will probably be more successful if his/her family adapts to a foreign environment too [29]-[30].

\section{Facilitators of Cross-cultural Relationships}

The researchers on intercultural management try to discover factors that facilitate cross-cultural relationships. The emphasis is put on people's mindset which affects the effectiveness of interpersonal contacts. Therefore, HRM practices directed at developing appropriate attitudes of personnel (i.e. recognizing, understanding, accepting cultural differences, and adapting to them) in a cross-cultural environment are underlined by the authors [11], [21].

MNCs adjust to cultural distance challenges in several ways, e.g. they determine the degree of control over foreign subsidiaries, autonomy and delegated authority, they use socialization, acculturation, and multicultural teams, manage expatriates and adapt HRM practices, etc. [16]-[20]. With regards to expatriate management, HRM practices that include appropriate selection mechanisms, pre-departure cross-cultural trainings, cross-cultural coaching on overseas assignments and repatriation management are of tremendous significance [30][34]. Frequent contacts of expatriates with their host country nationals (HCNs) proved to have a positive effect on their adjustment as well [35]. Moreover, recurring as well as continuous and intense interactions positively affect crosscultural relationships since they may weaken the cultural stereotypes [15], [39]. Notwithstanding the noticeable ineptitude or reluctance among MNCs to develop HCNs, the scholars also suggest investing in the local skills in foreign subsidiaries, e.g. by implementation of international career management programs [36]-[38].

Interpersonal contacts within a MNC's system can be improved by the development of common orientation, i.e. corporate culture that serves as a bridge between multiple and diverse subcultures of a MNC's units. (Common orientation does not mean homogenous corporate culture [40].) Concerning corporate culture, the researchers recommend, among other things, that a balance between global integration and cultural differentiation and localization needs to be found [11]. Furthermore, such a culture should be accepted, cope with changes but not necessarily does it have to be strong [10], [41]. From the organizational angle, MNCs should create a socalled multicultural organization to deal with diversity and cultural complexity and consequently to enhance the quality of cross-cultural interactions [5], [21].

Numerous authors claim that effective cross-cultural relationships can be established if an individual possesses a specific ability that is termed cultural intelligence, cultural competence, intercultural communication competence, intercultural effectiveness, etc. [19], [28], [32], [42]-[43]. Therefore, HRM practices in MNCs should support selection of workforce with the appropriate level of $\mathrm{CC}$, which should be further developed through a cross-cultural training [19] or during the learning process in multicultural teams [42]. Referring to MNCs, CC is perceived as a strategic competence affecting their operations [42].

\section{EMPIRICAL FINDINGS}

\section{A. A Brief Description of the Research Project [44]}

This section reports the empirical findings from the research project, whose major research problem was "Cultural barriers in functioning of MNCs foreign subsidiaries located in Poland". The research was conducted in winter at the end of the year 2009. Its goals included the following:

1) the identification of sources and areas of occurrence of the barriers to cross-cultural interactions in MNCs' foreign subsidiaries,

2) the evaluation of significance of the barriers,

3) the analysis of the methods used by the participants of the cross-cultural relationships aimed at identifying and overcoming cultural barriers.

Fig. 4 describes the research questions of the project.

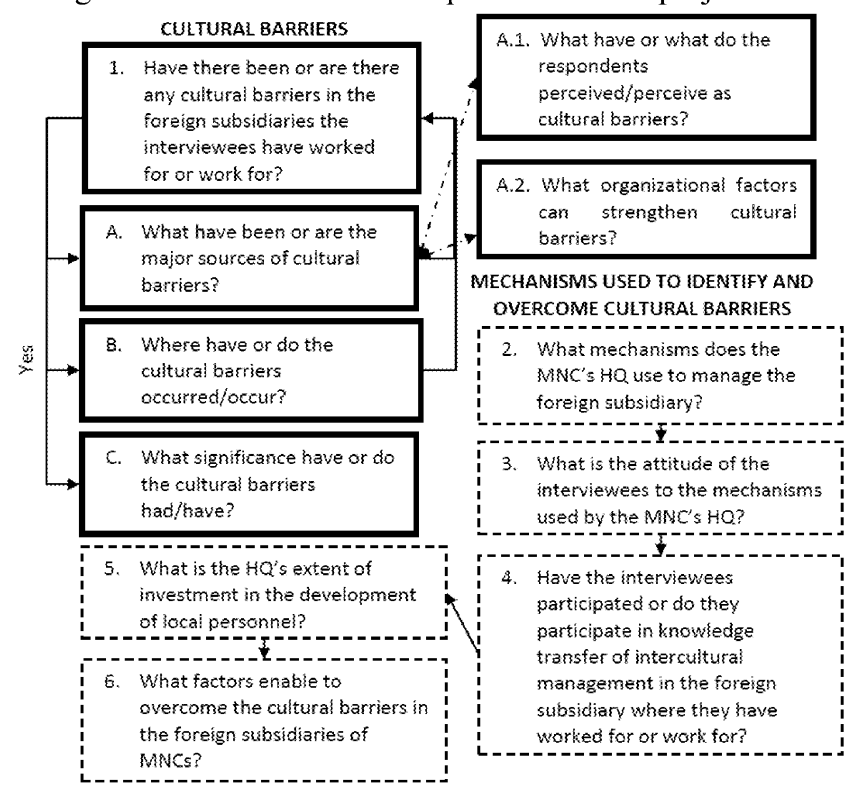

Fig. 4. Research questions.

10 types of cross-cultural interactions were analyzed, including both direct and indirect contacts (the order below reflects the interviewees' most frequent types of cross-cultural contacts):

1) multicultural face-to-face and virtual meetings (e.g. video- or teleconferences),

2) business trips abroad,

3 ) interactions in multicultural teams along with virtual 
ones,

4) office contacts within the MNCs (e.g. via e-mail, fax, intranet, etc.),

5) official duties carried out under the MNC's procedures,

6) subordinate-superior relationships, where one side is from a different national culture,

7) multicultural trainings,

8) office contacts with the MNCs' external stakeholders,

9) participation in international career management programs,

10) cross-cultural negotiations.

The non-probabilistic sample comprised 48 foreign subsidiaries that have run their operation in Poland for many

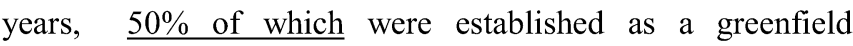
investment and the remaining ones as M\&As. Approximately $48 \%$ of the subsidiaries in the sample have had their HQ in Europe (including $43.8 \%$ in European Union), 18.8\% have had the North-American capital origin, $12.5 \%$ of the sample stated for Asian MNCs' subsidiaries and the remaining part for the entities with mixed capital. The sample was mostly made up of large incorporated enterprises which represented various sectors, including both manufacturing and services ones.

The method applied to collect the data was semi-structured interviews (about 1.5 hours per each interview). The interviewees were top and middle-level managers and specialists working for the MNCs' subsidiaries, mainly Poles (in the majority of cases one person per each subsidiary). They represented various functional departments. More than $40 \%$ of the respondents had more than 4.5 years of experience in service in the MNCs. Furthermore, the majority of the interviewees had had international experience before in the form of overseas business trips, life abroad or work for MNCs or work abroad. Such a foreign exposure of the respondents could have affected their perception of the cultural barriers and later their CC.

\section{B. Barriers to Cross-cultural Relationships according to the Research Findings}

The research disclosed that the interviewees observed the cultural barriers in their subsidiaries. These impediments referred to cultural distance embedded barriers, organizational barriers as well as individual rooted ones.

With regards to the first group of the barriers, $63.6 \%$ of the respondents noticed cultural distance as differences in behaviors of the foreigners caused by their national cultures that were the reason for some types of problems at work, yet relatively not frequent and severe. The interviewees witnessed the cultural differences concerning [45]:

- the superior role and his/her leadership style,

- the approach to delegation of authority,

- preferences for the decision-making style,

- preferences for the scope and the frequency of information flow between the HQ and a subsidiary,

- the attitude towards women,
TABLE I. ORGANIZATIONAL BARRIERS ACCORDING TO THE RESEARCH FINDINGS

\begin{tabular}{|l|}
\hline $\begin{array}{c}\text { Examples of organizational barriers in the analyzed MNCs' } \\
\text { subsidiaries }\end{array}$ \\
\hline - institutional ethnocentrism observed in the behaviors of the HQ \\
revealing its cultural domination approach to managing foreign \\
subsidiaries, \\
- insufficient understanding of the Polish specificity (i.e. general and the \\
task environment) by the HQ or expatriates, and as a result, ineffective \\
attempts to instill MNCs' organizational solutions into the Polish \\
subsidiaries, \\
- dissonance between the declared strategic predisposition and the actual \\
actions, \\
- integration problems concerning the organizational cultures with regards \\
to MNCs that used M\&As and consequently a culture gap, \\
- limitations of HRM practices, i.e.: ineffective recruitment, promotion \\
(e.g. ethnocentrism), and evaluation requirements, problems with \\
selection and utilization of expatriates, \\
- an insufficient communication system in the form of an ineffective use of \\
a MNC's functional language, difficulties with literal translation that can \\
lead to communication noises and time-consuming and costly \\
communication
\end{tabular}

Above are the answers to the research questions 1, A, and A.1 (see Fig. 4)

- life priorities reflected at work versus personal life dilemma,

- preferences for the necessity and the scope of formalization,

- the importance attached to internal and external interpersonal relationships,

- the differences in HRM's approach (hard vs. soft), perception of feedback,

- the differences in verbal and non-verbal behavior, communication styles, practices, work styles, foreigners' expectations. For example, one of the interviewees noticed [44]: "A lively gesticulation and uproariousness of the French made some members of the meeting nervous. They found it as an attack and, instead of looking for a solution, they stiffened in their positions. They did not have knowledge of typical French expressiveness and their specific verbal communication style. Moreover, the French were in their element, speaking their native language. If the interpreter was absent, his or her role was taken by someone else from the team, which was not accepted by the Poles. They felt weakened in the discussion." A remark of a few interviewees is worth mentioning, namely that when interacting with the representatives of a different culture it is hard to distinguish a behavior motivated by one's personality from a behavior influenced by his/her culture. As indicated in the literature review [9], [10], this is a consequence of an individual mental programming by genetic predisposition (human nature) and personality..

The analysis of the interviews allowed to identify the cultural barriers that were affected by organizational factors (see Table 1) [45]. Although the ethnocentric predisposition was perceived as the most troublesome, which is in accordance with the prior research [19], [23], the research also revealed that each type of strategic mindset can cause barriers to crosscultural interactions, partly due to the observed discrepancy between the declarations and the actual performance. Another 
reason could be a lack of adjustment between specific environmental requirements and the strategic predisposition of a MNC [44]. For instance, one of the interviewees noticed: "The central that declares a geocentric attitude is not always prone to increase the subsidiary's autonomy in decisions making process if the local adaptations are required by circumstances" [44]. With respect to regio- or geocentric predispositions, the global integration imperative that forces the HQ to lower costs was a thorny issue. The subsidiaries' personnel hardly accepted that the MNC's interest took precedence over the local interests, which sometimes led to a situation where the subsidiaries' employees were not rewarded adequately to their efforts. These produced tensions in mutual relationships between the parent company and its affiliates [15].

According to the research findings, the organizational solutions (e.g. a company's procedures, management methods and systems) became barriers to the cross-cultural interactions in a MNC's system if [15]:

- there was an overwhelming belief in the HQ in the universality of promoted solutions,

- the HQ exhibited rigidity of attitudes,

- solutions were forced without questioning their applicability,

- issues raised by the subsidiaries (e.g. different local law requirements) were ignored,

- the HQ could not understand that meeting its requirements might have overloaded its subsidiary.

Integration problems as consequences of a culture gap emphasize the significance of implementation of accepted corporate culture in MNCs. The research disclosed several barriers in this area. There were several reasons for reluctance among the MNC s' personnel to corporate mores and behaviors, namely their skepticism and suspicions [15]:

- about the universality of the customs promoted in the organizational culture, and as a result, their applicability referring to the local specifics of a subsidiary,

- due to insufficient trainings or the cultural dominance approach applied to implement a corporate culture,

- caused by a dissonance between the declarations and the actual actions, and consequently, the lack of belief in the authenticity of promoted values and norms.

With regards to HRM practices the interviewees reported barriers concerning the development of local employees [44], [45]:

- limitation of training policy: 1) ineffective corporate training due to the lack of ability to properly identify the training needs and neglecting the local specificity; 2) the training costs covered by the local budgets that in the face of cut-throat competition within a MNC's system could have led to reduction of investment in the local personnel since: "In a MNC a subsidiary must prove its usefulness." [44]; 3) a formal training in the intercultural management was not available in all the analyzed subsidiaries (only 20.8\% of the parent companies of the subsidiaries in the sample offered such a training),

- the promotion paths not adjusted to the requirements of the subsidiaries' employees, e.g. their low need for mobility or a high level of basic needs,

- limitations of international career management programs, due to: 1) an ethnocentric policy of promotion that set PCNs in a privileged position compared to $\mathrm{HCNs}$ when a candidate for promotion was considered; 2) an insufficient acquaintance of the parent company's language (despite the functional language was different from the parent company onc) by an employee posed a barrier to his/her promotion within a MNC's structure.

In spite of the limitations of HRM practices described above, the interviewees admitted that investments in the local personnel occurred in their subsidiaries and what is more, they felt job content mainly due to the fact that they could satisfy their need for career growth. This factor could have positively affected their attitude to the companies they worked for and therefore the perception of the barriers to cross-cultural relationships within MNCs. Nevertheless, the research showed that the barriers, although noticed by the interviewees, were not perceived as severe. The interviewees were still satisfied with their job and appreciated the cross-cultural interactions (93.1\% of the interviewees saw such an interaction as satisfactory). Moreover, the contacts with foreigners were mentioned as a source of the respondents' job content [44].

Cross-cultural relationships involve participants in a communication process that can be burdened with barriers. In the analyzed subsidiaries the interviewees mentioned communication as the most obvious area where the barriers were apparent. The following obstacles to communications were observed by them [44]:

- an insufficient acquaintance of the technical/branch language by external interpreters that sometimes caused noises in communication, especially the written one that required translation of documentation,

- usage of a colloquial language which was not comprehendible to non-native speakers,

- ambiguity of words led to problems with translations/interpretations,

- an insufficient acquaintance of the functional language by the contractors or a MNC's employees,

- reluctance of some of the MNC s' employees to use the functional language,

- some means of communication, i.e. tele- or videoconference, produced noises due to problems with the quality of transmitted signals,

- some evidence of an ethnocentric attitude observed in communication such as language carelessness of the nativespeakers who did not pay attention to be understood properly and were less tolerant to the mistakes made by non-native speakers or their tendency to speak the native language during meetings where foreigners were present. 
Furthermore, the respondents noticed that cross-cultural communication can be costly and time-consuming due to required translations/interpretations and the necessity to use various means of communication at the same time to increase the effectiveness of this process. Some interviewees also admitted that foreigners might associate the level of intelligence with the extent to which a person was fluent in their native language (a similar observation was also raised by some scholars [46]). Therefore, such a person could have been perceived as more professional, he/she was evaluated higher and had a greater chance for promotion in a MNC. Hence, some of the respondents claimed that their MNC's promotion policy was ethnocentric.

With regards to individuals, the research revealed the following individual rooted barriers [45]:

- misperception/misinterpretation/misevaluation in the form of the interviewees' tendency to make assumptions in crosscultural interactions, at least at the beginning; $80 \%$ of the respondents acknowledged that they had had a preconceived notion of the foreigners' behavior before their first contact with them and, what is more, for $51.2 \%$ of the respondents the factual relationships were different from the ones they had expected; as a result $68.9 \%$ of them changed their notion after the actual contacts; this factor enhanced their interactions with foreigners, which is in conformity with some scholars' observation stated in the literature review section (see [21], [26]-[27], [42]) that experience contributes positively to the improvements of cross-cultural relationships.

- ethnocentric attitude 1) of the Polish employees towards the employment policy in subsidiaries; $59.1 \%$ of the interviewees expressed a preference that the best posts in their organizations should be occupied by Poles, however they allowed for a possibility that the post of Chief Executive Officer in their subsidiaries could be held by a foreigner; 2) of the foreigners who manifested their superiority over the Poles, e.g. by criticizing the qualifications of the Polish employees; according to an interviewee, it is a typical situation that managers from Western Europe or North America view ideas of Eastern Europe managers as inferior, (this observation was based on actual experience of an interviewee during his work in multicultural teams; he recommended people from East Europe express their opinion after the Americans or West Europeans to prevent being seen as insistent or importunate),

- weak communication skills among the MNCs' employees, including a lack of ability to speak the local language among the expatriates, which was perceived by some respondents as an ineptitude to establish a closer relationship with a subsidiary's personnel, to understand their mood and react accordingly.

All the barriers to cross-cultural relationships in the MNCs mentioned above could have been avoided or overcome by the means discussed in the subsequent section of this paper.

\section{Facilitators of Cross-cultural Relationships according} to the Research Findings

The research allowed for the indication of some facilitators of cross-cultural interactions in MNCs from the angle of their subsidiaries. They have been arranged according to the sources as well as the areas of occurrence of the cultural barriers. The reported empirical finding address questions 2, 3, and 6 (see Fig. 4).

Several methods of adaptations of MNCs to cultural distance have been depicted in the literature review section. The effectiveness of the adaptation method is likely to depend on many situational factors (i.e. industry requirements, a role assigned to a subsidiary, a MNC's organizational model, competences of the HQ in the use of a given mechanism, etc.). Situational factors were significant in the case of the analyzed subsidiaries as well. The interviewees once assessed a method as effective and another time as ineffective depending on a specific situation of a subsidiary and their personal experience. For example, multicultural teams (MTs) were highly valued by most of the respondents. Nevertheless, a number of them observed minuses of their functioning that lowered the effectiveness of MTs such as indolence in the decision making process, problems with recognizing the internal structure when adaptation to a new situation was required, the necessity of indirect and therefore frequently less effective communication due to a geographical dispersal of some MTs [44]. Regardless of the situational factors, most of the interviewees acknowledged the following as an effective mechanism of adaptation to a cultural distance concerning management of foreign subsidiaries: operational control combined with delegated authority in operational performance, financial control, coordination of allocated resources and assigned tasks, a frequent communication with the HQ and other affiliates, knowledge transfer to a subsidiary [44]. 
As depicted in the theoretical section of this paper, scholars emphasize HRM practices' role in improving cross-cultural relationships. Table 2 [44] lists propositions concerning an increase of effectiveness of HRM practices in managing expatriates and subsidiaries' employees. Moreover, Table 2 includes recommendations referring to the development of accepted corporate culture in a MNC's system.

Regarding expatriate management, the following can be added, basing on the empirical findings [44]:

- the HQ should clearly communicate an expatriate's tasks to its subsidiarics' cmployecs and why they are important to avoid confusions/suspicions about his/her role,

- a localization of management is recommended, thus an expatriate should prepare his/her successor from among the local personnel; some of the interviewees have stressed that there is no more shortage of Polish qualified personnel for managerial positions (a similar objection to hiring expatriates along with recommendation to prepare a local successor were raised in the case of MNCs investing in China [47]),

- an expatriates' compensation package may be a huge burden to the subsidiary budget, therefore the HQ should increase it.

Organizational solutions can facilitate cross-cultural interactions in MNCs' subsidiaries. The research showed that organizational solutions enhanced such an interaction if they had been [15]:

- tested out in many local environments before implementation in a given unit,

- flexibly applied and adjusted in accordance with the circumstances, which needed a continuous verification and modification to cope with changes,

- accompanied by successful HRM practices, including expatriate management,

- supported by an accepted MNC's culture,

- supported by the HQ's appropriate attitude, i.e. openness to the local solutions.

Moreover, the internal cooperation in the MNCs could have been improved if the subsidiaries' managers were fully aware of their role as a bridge/liaison between the HQ and their unit. Additionally, they should have pursued the grow strategy of the position of their subsidiary enacted in a MNC's system.

With regards to individuals the interviewees suggested the following [44]:

- concerning communication: being prepared for a discussion, i.e. knowing the subject and the agenda, reading minutes; self-improvement of communication skills; usage of plain language (i.e. simple words set with accent and cadence that are listener-friendly, in a proper context and without idioms, phrases, metaphors and colloquialisms that may be difficult to understand, e.g. if English is the functional language, individuals should use so-called International English);

- concerning attitudes: being empathic and cooperative, open to learning, changes and multiculturalism.
TABLE II. PROPOSITIONS OF IMPROVEMENTS OF HRM PRACTICES IN MANAGING MNCS' FOREIGN SUBSIDIARIES

\begin{tabular}{|c|c|}
\hline $\begin{array}{c}\text { Propositions of improvements } \\
\text { of expatriate management in } \\
\text { foreign subsidiaries - the role } \\
\text { of HRM practices }\end{array}$ & $\begin{array}{l}\text { Enablers in the development and } \\
\text { implementation of accepted } \\
\text { corporate culture - the role of } \\
\text { HRM practices }\end{array}$ \\
\hline $\begin{array}{l}\text { - HRM practices should be } \\
\text { aimed at selecting an expatriate } \\
\text { who has higher skills than the } \\
\text { host country managers; he/she } \\
\text { should support knowledge } \\
\text { transfer to a foreign subsidiary } \\
\text { and actively invest in the } \\
\text { development of the local skills. } \\
\text { - HRM practices should help in } \\
\text { selecting an expatriate who } \\
\text { understands the specific } \\
\text { environment of a host country (at } \\
\text { least the basic knowledge of the } \\
\text { subsidiary's legal, economic and } \\
\text { cultural environment) and who is } \\
\text { open to cooperation with the local } \\
\text { cadre. } \\
\text { - HRM practices should } \\
\text { enhance an expatriate's } \\
\text { motivation for working on } \\
\text { overseas assignments; a lack of } \\
\text { motivation makes him/her } \\
\text { inefficient and discourages the } \\
\text { local cadre. } \\
\text { - HRM practices should enable } \\
\text { training for an expatriate in how } \\
\text { to be authentic in his/her role to } \\
\text { gain credibility of the host } \\
\text { country cadre. } \\
\text { - HRM practices should support } \\
\text { awareness among the HQ's } \\
\text { managers of the complex role of } \\
\text { expatriates; they must be aware } \\
\text { that sound communication } \\
\text { between the parent and its } \\
\text { subsidiary via an expatriate is a } \\
\text { matter of importance. }\end{array}$ & $\begin{array}{l}\text { - An appropriate selection of } \\
\text { employees contributes to the } \\
\text { development of accepted corporate } \\
\text { culture. } \\
\text { - HRM practices should foster } \\
\text { attraction and maintenance of } \\
\text { personnel with well-developed CC. } \\
\text { - HRM practices should further } \\
\text { support the development of CC of a } \\
\text { MNC's personnel. } \\
\text { - HRM practices should enable } \\
\text { transfer of cross-cultural knowledge } \\
\text { within a MNC's system by } \\
\text { encouraging its employees to share } \\
\text { their experience. } \\
\text { - HRM practices should be } \\
\text { directed at improving its } \\
\text { employees' communication skills, } \\
\text { including speaking the functional } \\
\text { language. } \\
\text { - HRM practices should } \\
\text { encourage a MNC's subsidiaries' } \\
\text { personnel to participate in the } \\
\text { international careers management } \\
\text { programs. } \\
\text { - Cultural knowledge should be } \\
\text { developed within a MNC's each } \\
\text { subsystem. } \\
\text { - A MNC's culture elements } \\
\text { should be attractive to the local } \\
\text { personnel. } \\
\text { - The implementation of a MNC's } \\
\text { culture requires an active } \\
\text { involvement of the local employees } \\
\text { in the process. } \\
\text { - The implementation of a MNC's } \\
\text { culture needs to be accompanied by } \\
\text { an appropriate training. } \\
\text { - A MNC's culture must be } \\
\text { authentic. Therefore, the actual } \\
\text { actions of managers must be } \\
\text { consistent with the values and } \\
\text { norms declared in the culture. }\end{array}$ \\
\hline
\end{tabular}

The propositions above address the research questions 6 (see Fig. 4)

\section{CONCLUSION}

\section{A. Implications of the Research Findings}

This paper provides several practical implications concerning management of MNCs' foreign subsidiaries, especially human interactions in a cross-cultural setting. This contributes to a better understanding of what determines the effectiveness of cross-cultural relationships within MNCs including foreign subsidiaries' viewpoint and their active role in the whole process. Firstly, it enumerates barriers to a mutual cooperation in MNCs basing on the literature review with the author's concept and provides the empirical findings. The organizational context of cross-cultural relationships that 
affects their effectiveness is particularly emphasized. It is also indicated that both the HQ's and subsidiaries' managers in MNCs bear responsibility for cross-cultural interactions since they can mould an organizational context where such an interaction occurs. Although the cultural barriers were not severe in the analyzed subsidiaries, the research showed which problems should attract more attention of MNCs' managers to enhance the quality of internal cooperation:

1) Ethnocentric mindset - it seems to be deeply rooted both at the organizational level and the individual one. In the analyzed subsidiaries it was manifested in HRM practices, communication, promoted solutions and values (a belief in universality of corporate solutions and values holds a hidden assumption of their superiority over a local perspective), and individual attitudes. From the organizational angle, it evokes difficulties with flexibility and adjustments.

2) Lack of authenticity, namely what has been declared contradicts what is actually enacted. This was observed by the interviewees with regards to the strategic predisposition of the HQ and the implementation of corporate culture. A lack of authenticity may have resulted in suspiciousness that negatively affects the local employees' perception of the parent company.

3) Development of local cadre - the interviewees claimed that their international career management programs were not attractive enough. Furthermore, the low percentage of the subsidiaries participating in formal knowledge transfer of the intercultural management is a puzzling fact.

Secondly, the research indicates facilitators of cross-cultural relationships (see Fig. 5).

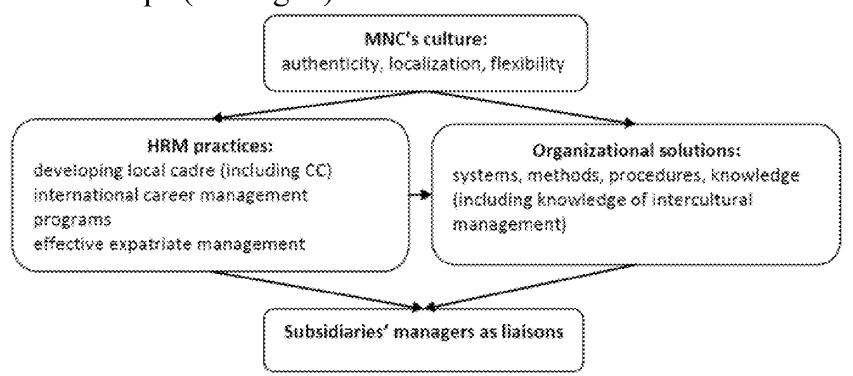

Fig. 5. Facilitators of Cross-cultural Relationships in MNCs.

\section{B. Limitations and Future Research}

Several limitations of the conducted study can be listed. First of all, the research project was relatively broad in scope and hence some issues were only sketched. Each barrier to and a facilitator of cross-cultural relationships could have been analyzed separately and explored in more detail. Secondly, this study used a qualitative type of research where, in most cases, a single person in each company was interviewed. The responses might therefore reflect individual opinions which were not shared in a whole company. Future research could be extended by an in-depth case-study in selected subsidiaries. While the size of the sample was also limited, future research may be enlarged by an increased number of units in the sample. Moreover, the research might be triangulated by surveying the HQ's managers. Thirdly, the empirical findings cannot be generalized because of the method applied to select the sample. Additionally, generalization is limited since the interviewees were mainly Poles and the subsidiaries were located in Poland. Therefore, the results may reflect a perspective on the issues under discussion specific to the Polish business environment or typical of transition economies (that can also point out the importance of this study). Finally, future research may be extended to subsidiaries in countries other than Poland.

\section{REFERENCES}

[1] G. K. Stahl, K. Makela, L. Zanderd, M. L. Maznevski, "A look at the bright side of multicultural team diversity", Scandinavian Journal of Management, no. 26, pp. 439-447, 2006.

[2] The Oxford Handbook of International Business, 2nd ed., A. M. Rugman, T. L. Brewer, Eds. New York: Oxford University Press, 2003.

[3] J. Birkinshaw, "Strategy and management in MNE subsidiaries," in The Oxford Handbook of International Business, 2nd ed., A. M. Rugman, T. L. Brewer, Eds. New York: Oxford University Press, 2003, pp. 380401.

[4] N. J. Adler, "A typology of management studies involving culture", Journal of International Business Studies, pp. 29-47, fall 1983.

[5] N. J. Adler, "Cross-cultural management: Issues to be faced", International Studies of Management and Organizations, vol. XIII, no. 1-2, pp. 7-45, 1983.

[6] W. Dorow, S. Blazejewski, "Global corporate cultures: management between cultural diversity and cultural integration", in Cultural Forum. Corporate Cultures in Global Interaction, L. Mohn, Ed. Gutersloh: Bertelsmann Foundation, 2003, vol. 3, p. 17.

[7] T. Novinger, Intercultural Communication. A Practical Guide, Austin: University of Texas Press, 2001, pp. 4-9.

[8] M. J. Hatch, "The Dynamics of Organizational Culture", Academy of Management Review, vol. 18, no. 4, pp. 657-693, 1993.

[9] H.-U. Zabel, "A model of human behaviour for sustainability", International Journal of Social Economics, vol. 32, is. 8, pp. 717-734, 2005.

[10] G. Hofstede, Culture's Consequences: Comparing Values, Behaviors, Institutions, and Organizations across Nations, Thousand Oaks, California: Sage, 2001, pp. 25-40.

[11] W. Dorow, S. Blazejewski, "Global corporate cultures: management between cultural diversity and cultural integration", in Cultural Forum. Corporate Cultures in Global Interaction, L. Mohn, Ed. Gutersloh: Bertelsmann Foundation, 2003, vol. 3, pp. 12-29.

[12] D. Cooper, L. Doucet, M. G. Pratt (2012, July 16), Understanding 'Appropriateness' in Multinational Corporations. Working Papers, pp. 1-41 and 7 (for the citation) Available: http://www.business.uiuc.edu/Working_Papers/papers/05-0122.pdf

[13] K. Yoshitake, "The advantage of active conformity as a communication strategy for compatibility between self-assertion and smooth interpersonal relationship", Japanese Journal of Psychology, no. 62, pp. 229-234, 1992.

[14] M. Rozkwitalska, "HRM in cross-border M\&As. The cultural barriers approach", presented at 10th Annual BMDA Conference "Winning Strategies in Challenging Times", Gdansk, Poland, May 10 - 11, 2012.

[15] M. Rozkwitalska, Intercultural Management Issues. Warszawa: Difin, 2012, ch. 2.

[16] S. Beechler, J. Z. Ynag, "The transfer of Japanese-style management to American subsidiaries", Journal of International Business Studies, vol. 25, pp. 467-491, 1994.

[17] I. Bjőrkman, G. K.Stahl, and E. Vaara, "Cultural differences and capability transfer in cross-border acquisitions: the mediating roles of capability complementarity, absorptive capacity and social integration", Journal of International Business Studies, vol. 38, pp. 658-672, 2007. 
[18] K. Uhlenbruck, "Developing acquired foreign subsidiaries: the experience of MNES in transition economies", Journal of International Business Studies, vol. 35, pp. 109-123, 2004.

[19] J. P. Johnson, T. Lenartowicz, and S. Apud, "Cross-cultural competence in international business: toward a definition and a model", Journal of International Business Studies, vol. 37, pp. 525-543, 2006.

[20] O. Shenkar, "Cultural distance revisited: towards a more rigorous conceptualization and measurement of cultural differences", Journal of International Business Studies, vol. 23, no. 3, pp. 519-535, 2001.

[21] N. J. Adler, A. Gundersen, International Dimensions of Organizational Behavior, 5th ed., International Edition: South Western, 2008, pp. 19, 73-86, 101-102, 274-282.

[22] D. B. McFarlin, P. D. Sweeney, International Management. Strategic Opportunities and Cultural Challenges, Boston - New York: Houghton Mifflin Company, 2006, p. 181.

[23] B. S. Chakravarthy, V. Perlmutter, "Strategic planning for a global business", Columbia Journal of World Business, pp. 3-10, summer 1985.

[24] J. Johanson, J. Vahlne, "The internationalization process of the firm - a model of knowledge development and increasing foreign market commitments", Journal of International Business Studies, vol. 8, pp. 23$32,1977$.

[25] H. G. Barkema, J. H. Bell, and J. M. Pennings, "Foreign entry, cultural barriers, and learning", Strategic Management Journal, Vol. 17, pp. 151 166, 1996.

[26] B. Toyne, "Host country managers of multinational firms: an evaluation of variables affecting their managerial thinking patterns", Journal of International Business Studies, 7, pp. 39-56, 1976.

[27] S. Magala, Cross-cultural Competence, New York: Routledge, 2005, p. 30.

[28] S. Ang, L. Van Dyne, C. K. S. Koh, K. Y. Ng, K. J. Templer, C. Tay, and N. A. Chandrasekar, "Cultural intelligence: its measurement and effects on cultural judgment and decision making, cultural adaptation and task performance", Management and Organization Review, vol. 3, is. 3, pp. 335-371, 2007.

[29] B. R. Peterson, "The use of expatriates and inpatriates in Central and Eastern Europe since the Wall came downs", Journal of World Business, no. 38, pp. 55-69, 2003.

[30] A. W. Andreason, "Married manager abroad", Industrial Management, vol. 49 , is. 2 , pp. $20-25,2007$

[31] M. Harvey, M. Novicevic, "Selecting expatriates for increasingly complex global assignments", Career Development International, vol. 6 /2, pp. 69-86, 2001.

[32] P.C. Earley, R. S. Peterson, "The elusive cultural chameleon: Cultural intelligence as a new approach to intercultural training for the global manager", Academy of Management Learning and Education, vol. 3, pp. 100-115, 2004.

[33] A. W. Andreason, K. D. Kinneer, "Repatriation adjustment problems and the successful reintegration of expatriates and their families", Journal of Behavioral \& Applied Management, vol. 6, is. 2, pp. 109126, 2005.

[34] H. Park, S. D. Hwangt, and J. K. Harrison, "Sources and consequences of communication problems in foreign subsidiaries: the case of United States firms in South Korea", International Business Review, vol. 5, is. I, pp. 79-98, February 1996.

[35] M. Festing, M. Maletzky, "Cross-cultural leadership adjustment - A multilevel framework based on the theory of structuration", Human Resource Management Review, vol. 2, is. 3, pp. 186-200, September 2011.

[36] E. Farndale, H. Scullion, P. Sparrow, "The role of the corporate HR function in global talent management", Journal of World Business, vol. 45, is. 2, pp. 161-168, April 2010.

[37] W. Harry, D. G. Collings, "Localisation: Societies, organizations and employees", in Global Staffing, H. Scullion, D. G. Collings, Eds., London: Routledge, 2006, pp. 7-116.

[38] D. G. Collings, M. J. Morley, P. Gunnigle, "Composing the top management team in the international subsidiary: Qualitative evidence on international staffing in U.S. MNCs in the Republic of Ireland", Journal of World Business, vol. 43, is. 2, pp. 197-212, March 2008.
[39] B.W. Stening, J. E. Everett, P. A. Longton, "Mutual perception of managerial performance and style in multinational subsidiaries", Journal of Occupational Psychology, pp. 255-263, December 1981.

[40] S. Scheffknecht, "Multinational enterprises - organizational culture vs. national cultures", International Journal of Management Cases, vol. 9, is. $3 / 4$, pp. $73-78,2007$

[41] D. E. Welch, L. S. Welch, "Commitment for hire? The viability of corporate culture as a MNC control mechanism", International Business Review, no. 15, pp. 14-28, February 2006.

[42] A. Bartel-Radic, "Intercultural learning in global teams", Management International Review, vol. 46, is. 6, pp. 647-677, 2006

[43] A. Mamman, "Socio-biographical antecedents of intercultural effectiveness. The neglected factors", British Journal of Management, vol. 6, pp. 97-114, 1995.

[44] M. Rozkwitalska, Bariery w zarządzaniu międzykulturowym. Perspektywa filii zagranicznych korporacji transnarodowych (Barriers in Intercultural Management. Multinational Corporations' Foreign Subsidiaries' viewpoint), Warszawa: Oficyna - Wolters Kluwer, 2011, ch. 4, 5, appendix 5, pp. 193, 231, 239 (for the citations).

[45] M. Rozkwitalska. (2010, November). Barriers of cross-cultural interactions according to the research findings. Journal of Intercultural Management, vol. 2, no. 2, pp. 37-52. Available: http://www.joim.pl/pdf/ROZKWITALSKAv2n2.pdf

[46] J. Brett, K. Behfar, and M. C. Kern, "Managing multicultural teams", Harvard Business Review, November 2006.

[47] T. Kühlmann, K. Hutchings, "Expatriate assignments vs localization of management in China. Staffing choices of Australian and German companies", Career Development International, vol. 15, is. 1, pp. 20-38, 2010 . 
Copyright of Annual International Conference on Enterprise Marketing \& Globalization is the property of Global Science \& Technology Forum and its content may not be copied or emailed to multiple sites or posted to a listserv without the copyright holder's express written permission. However, users may print, download, or email articles for individual use. 